\title{
PRINCIPIOS, OBJETIVOS Y DERECHOS. OTRA VUELTA DE TUERCA
}

\author{
Juan Ruiz Manero \\ Universidad de Alicante
}

RESUMEN. En el libro publicado en 1996 Las piezas del Derecho, Manuel Atienza y Juan Ruiz Manero criticaron la tesis de Robert Alexy de los principios como mandatos de optimización y sostuvieron que tal caracterización resultaba adecuada únicamente para aquellos principios (en sentido genérico) que es usual llamar directrices o normas programáticas, pero no para lo que los autores llamaban principios en sentido estricto. Esta crítica ha sido discutida después en diversos trabajos entre los que Ruiz Manero destaca artículos debidos al propio Robert Alexy, a Gloria Lopera y a Josep Aguiló, así como una entrevista a Alexy realizada por Atienza. En este artículo, Ruiz Manero trata de responder a las críticas contenidas en estos trabajos a la posición desarrollada por Atienza y él mismo. Entre los puntos discutidos vale la pena mencionar los siguientes: la contribución de principios en sentido estricto y de directrices a la configuración de derechos; los sentidos en los que cabe hablar de modalidades graduables de cumplimiento de una norma; la distinción, a propósito de las relaciones entre acciones y estados de cosas, entre relaciones conceptuales y relaciones causales; la vinculación entre diferentes tipos de principios y diferentes tipos de valores.
Abstract. In "Las piezas del Derecho", published in 1996, Manuel Atienza and Juan Ruiz Manero critisized Robert Alexy's thesis of principles as optimization commands, and they maintained that such a characterization was only appropriate with regard to those principles (in the generic sense) which are usually called policies or programmatic norms, but the said characterization were not appropriate with regard to what the authors called principles in the strict sense. This criticism has since been queried in a number of papers, amongst which Ruiz Manero mentions articles by Robert Alexy himself, by Gloria Lopera and by Josep Aguiló, as well as an interview with Alexy carried out by Atienza. In this article, Ruiz Manero seeks to answer the criticism which these papers contain of his and Atienza's position. Of the points discussed, the following are worth mentioning: the contribution of principles in the strict sense and policies to the shaping of rights; the senses in which one can speak of gradable forms of fulfilling a norm; the distinction, made regarding the relationships between actions and the state of affairs, between conceptual relationships and causal relationships; the connection between different types of principles and different types of values. 


\section{Introducción. La tesis de Alexy y nuestra crítica}

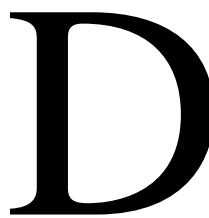

esde la publicación de la primera edición de Las piezas del Derecho $^{1}$-y aun antes, en trabajos que constituyeron versiones preliminares de lo que acabó siendo el primer capítulo de ese libro²- Manuel Atienza y yo mismo sometimos la tesis de Robert Alexy de los principios como mandatos de optimización a una crítica directa. Crítica directa que hemos mantenido, con cambios de acento pero no sustantivos, y con algún desarrollo colateral, en trabajos posteriores ${ }^{3}$. Como es bien sabido, la teoría de los principios de Alexy tiene como uno de sus puntos centrales la consideración de que los principios son mandatos de optimización que pueden cumplirse en diversos grados, mientras que las reglas exigen cumplimiento pleno. En los propios términos de Alexy, el "núcleo" o "punto decisivo" de la distinción entre reglas y principios sería el siguiente:

"Los principios son normas que ordenan que se realice algo en la mayor medida posible, en relación con las posibilidades jurídicas y fácticas. Los principios son, por consiguiente, mandatos de optimización que se caracterizan porque pueden ser cumplidos en diversos grados y porque la medida ordenada de su cumplimiento no sólo depende de las posibilidades fácticas, sino también de las posibilidades jurídicas. El campo de las posibilidades jurídicas está determinado a través de principios y reglas que juegan en sentido contrario. En cambio, las reglas son normas que exigen un cumplimiento pleno $\mathrm{y}$, en esa medida, pueden ser sólo cumplidas o incumplidas. Si una regla es válida, entonces es obligatorio hacer precisamente lo que ordena, ni más ni menos. Las reglas contienen por ello determinaciones en el campo de lo posible fáctica y jurídicamente [...]. Si se exige la mayor medida posible de cumplimiento en relación con las posibilidades jurídicas y fácticas, se trata de un principio; si sólo se exige una determinada medida de cumplimiento, se trata de una regla"4.

Pues bien: a este planteamiento oponíamos Atienza y yo la necesidad de distinguir entre dos tipos de principios -principios en sentido estricto y di-

${ }^{1}$ M. Atienza y J. Ruiz Manero: Las piezas del Derecho. Teoría de los enunciados jurídicos, Ariel, Barcelona, 1996. En adelante me referiré a este libro como Las piezas. Hay una segunda edición de 2004 que incorpora diversos cambios y añadidos.

${ }^{2}$ M. Atienza y J. Ruiz Manero: "Sobre principios y reglas”, en Doxa, no 10, 1991; "Objeciones de principio. Respuesta a Aleksander Peczenik y Luis Prieto Sanchos”, en Doxa, $\mathrm{n}^{\circ}$ 12, 1992; “Tre approcci ai principi di diritto”, en Analisi e diritto. Ricerche di giurisprudenza analitica, 1993.

${ }^{3}$ M. Atienza y J. Ruiz Manero: "Rules and Principles Revisited”, en Associations. Journal for Legal and Social Theory, vol. 4, n 1, 2000; Ilícitos atípicos. Sobre el abuso del derecho, el fraude de ley y la desviación de poder, Trotta, Madrid, 2000.

${ }^{4}$ R. Alexy: “Sistema jurídico, principios jurídicos y razón práctica”, en Doxa, nº 5, 1988, pp. 143-44. En el mismo sentido, Teoría de los derechos fundamentales, trad. cast. de E. Garzón Valdés, Centro de Estudios Constitucionales, Madrid, 1993, pp. 86 ss. 
rectrices o normas programáticas- y ello tanto si contemplamos las normas desde una perspectiva estructural (esto es, atendiendo a cómo están internamente organizados sus elementos) como si lo hacemos desde la perspectiva de la manera cómo pretenden incidir en el razonamiento práctico de sus destinatarios (esto es, atendiendo a las razones para actuar de que pretenden proveer). Desde la primera perspectiva, las normas que llamamos principios en sentido estricto están compuestas, de acuerdo con nuestra reconstrucción, por un antecedente en el que no figura otra cosa más que el que exista una posibilidad de realizar (u omitir) una cierta acción y un consecuente en el que figura el deber prima facie de realizar (u omitir) tal acción. De esta forma, los principios en sentido estricto pueden ser vistos como normas categóricas (en el sentido de von Wright ${ }^{5}$, esto es, que no establecen condiciones de aplicación distintas de las que se derivan de su contenido) que generan deberes meramente prima facie; si, en relación con un cierto caso, deseamos saber si ese deber prima facie deviene deber concluyente hemos de añadir al antecedente, constituido por la existencia de una posibilidad de realizar (u omitir) la acción modalizada deónticamente en el consecuente, una cláusula de “a menos que”: el deber prima facie deviene deber concluyente siempre que sobre el caso en cuestión no incida otro principio que tenga, en relación con él, un peso mayor y que, por ello, derrote, en relación con el caso, al principio bajo consideración. De esta forma, los principios en sentido estricto pueden ser vistos como normas hipotéticas (asimismo en el sentido de von Wright ${ }^{6}$, esto es, que establecen condiciones de aplicación adicionales a aquellas que se derivan de su contenido) que generan deberes concluyentes. La diferencia con las reglas (que también establecen condiciones de aplicación adicionales a aquellas que se derivan de su contenido) es que, en el caso de las reglas, esas condiciones de aplicación están determinadas (o, lo que es lo mismo, se presentan, como preferíamos decir en Las piezas, en forma cerrada), mientras que en el caso de los principios en sentido estricto tales condiciones de aplicación están indeterminadas (o, lo que es lo mismo, se presentan, como preferíamos decir en Las Piezas, en forma abierta). De lo que se sigue la tan conocida circunstancia de que, así como la manera en que una regla se aplica a ciertos casos es mediante

\footnotetext{
${ }^{5}$ G. H. von Wright: Norma y acción. Una investigación lógica, trad. cast. de P. García Ferrero, Tecnos, Madrid, 1979, p. 91: "Llamaremos a una norma (que no sea una regla ideal) categórica si su condición de aplicación es la condición que tiene que cumplirse para que exista una oportunidad de hacer aquello que constituye su contenido, y ninguna otra condición”.

${ }^{6}$ Ibíd., p. 91: "Llamaremos a una norma (que no sea una regla ideal) hipotética si su condición de aplicación es la condición que ha de cumplirse para que exista una oportunidad de hacer aquello que constituye su contenido y alguna otra condición adicional" (corrijo aquí una errata evidente de la traducción castellana).
} 
la subsunción de estos en aquella, la manera en que un principio se aplica a ciertos casos es mediante su ponderación en relación con cada uno de esos casos con otros principios que resulten concurrentes. Si las reglas pueden aplicarse sin ponderación es porque en ellas se encuentran determinadas las propiedades genéricas que constituyen sus condiciones de aplicación; como tales propiedades genéricas no se encuentran determinadas en el caso de los principios, la ponderación es aquí inescapable. Las reglas pueden, pues, ser vistas como razones perentorias ${ }^{7}$ (como razones para hacer lo ordenado excluyendo la deliberación sobre otras razones en pro o en contra de ello) precisamente porque determinan en qué condiciones debe hacerse (concluyentemente) lo ordenado; los principios no pueden ser vistos más que como razones de primer orden (como razones para hacer lo ordenado cuyo peso frente a otras razones en contra de ello no puede establecerse más que mediante deliberación) precisamente porque no determinan en qué condiciones debe hacerse (concluyentemente) lo ordenado. Pero, si en relación con un cierto caso, el principio bajo consideración no resulta derrotado por otros eventualmente concurrentes, éste exige, decíamos en Las Piezas, un cumplimiento pleno: la acción u omisión ordenada se realiza o no se realiza, esto es, se cumple o no se cumple con lo exigido por el principio, pero no caben modalidades graduables de cumplimiento. Pensemos, por ejemplo, en el caso constituido por un concurso para el reclutamiento de médicos para hospitales de la Seguridad Social al que aspiran titulados que religiosamente se definen como testigos de Jehová y que, por tanto, consideran que las transfusiones sanguíneas están sujetas a una prohibición divina absoluta. Se concordará en que aquí concurren, de un lado, el principio de prohibición de trato desigual por razón de las creencias religiosas y, por otro, el principio de protección de la vida humana. Supongamos que entendemos que las cosas se plantean de forma distinta en el caso de los nutricionistas, por un lado, y en el de los especialistas en cuidados intensivos, por otro. En el caso de los nutricionistas entendemos que un médico testigo de Jehová no supone un riesgo apreciable para la vida de los pacientes, pues en esta especialidad

\footnotetext{
${ }^{7}$ Lo que no excluye que, en relación con ciertos casos pueda ocurrir que, aun constituyendo prima facie instancias del caso genérico configurado en las condiciones de aplicación de la regla, no estén, sin embargo, dentro del alcance justificado de la misma, bien (1) porque las principales razones que respaldan la regla no se apliquen en absoluto en ese caso, bien (2) porque aun aplicándose esas razones se aplique también otra razón más fuerte (que no pertenece a las que respaldan la regla) y que exige una distinta solución normativa, bien (3) porque las razones que respaldan la regla se aplican en un grado ínfimo o insignificante. Al tratar de responder aquí a críticas referidas a nuestra teoría de los principios, y no a nuestra teoría de las reglas, dejaré de lado por completo estas complicaciones. En todo caso, sobre ello véase M. Atienza y J. Ruiz Manero Ilícitos atípicos, cit., y también Ángeles Ródenas: "Entre la transparencia y la opacidad. Análisis del papel de las reglas en el razonamiento judicial”, en Doxa, n²1/I, 1998.
} 
no es usual la prescripción de transfusiones sanguíneas y, en todo caso, al no tener los tratamientos carácter de urgencia, siempre podría intervenir un médico de distinta adscripción religiosa. El caso es distinto, nos parece, en el caso de los médicos especialistas de cuidados intensivos. Estos tienen que tomar rápidamente decisiones en contextos en los cuales la realización o no de una transfusión sanguínea es, literalmente, cuestión de vida o muerte para los pacientes. Supongamos que entendemos que, en virtud de estas consideraciones, en el caso del reclutamiento de nutricionistas prevalece el principio de prohibición de trato desigual por razón de las creencias religiosas, mientras que en el caso del reclutamiento de especialistas en cuidados intensivos prevalece el principio de protección de la vida humana. En el primer caso (en el de los nutricionistas), pues, excluir a los testigos de Jehová estaría concluyentemente prohibido. En el segundo caso (en el de los especialistas en cuidados intensivos) excluir a los testigos de Jehová sería concluyentemente obligatorio. Y estas prohibiciones y obligaciones concluyentes no pueden más que cumplirse o incumplirse. No hay una tercera posibilidad; no hay modalidades graduables de cumplimiento.

Las cosas son distintas si lo que examinamos no son lo que llamábamos principios en sentido estricto, sino las directrices o normas programáticas, entendiendo por tales las normas que establecen la obligatoriedad de perseguir determinados objetivos colectivos, esto es, de maximizar ciertos rasgos o propiedades del mundo social. Por ejemplo, la disposición constitucional que ordena que la política económica esté orientada al pleno empleo. De acuerdo con lo que sosteníamos en Las Piezas, estas normas deben reconstruirse como no conteniendo, en su antecedente, más que el que haya una oportunidad de realizar la conducta ordenada en el consecuente (contribuir a maximizar el empleo). Son, pues, de nuevo en el sentido de von Wright, normas categóricas, pues no contienen en su antecedente ninguna propiedad adicional a la de que haya una oportunidad de realizar la conducta ordenada en el consecuente. Esta conducta ordenada en el consecuente presenta, por su parte, cuatro rasgos importantes. Primero, no se trata de una acción, sino de un estado de cosas que puede mantener relaciones causales con acciones muy heterogéneas entre sí: puede fomentarse el pleno empleo mediante políticas salariales, comerciales, educativas, fiscales, de función pública, etc. Segundo, estas acciones, a su vez, pueden mantener relaciones causales asimismo muy heterogéneas con estados de cosas ordenados por directrices diversas: cierta política fiscal puede, de entrada, contribuir a fomentar el pleno empleo, pero contribuir a deteriorar la estabilidad económica, estado de cosas al que apunta otra directriz constitucional; y este deterioro de la estabilidad económica puede, a su vez, acabar teniendo efectos negativos sobre el empleo. Tercero, la propiedad que caracteriza al estado de cosas 
ordenado por cada directriz es una propiedad graduable y lo ordenado es maximizar tanto como sea posible esa propiedad, trazando políticas que articulen la procura de esa maximización con la procura de la maximización de las propiedades caracterizadoras de los estados de cosas cuya persecución ordenan otras directrices. Cuarto, ese deber de maximización no es un deber meramente prima facie, sino concluyente.

De forma que la necesidad de deliberación, común a todos los principios, se plantea de forma distinta según que se trate de principios en sentido estricto o de directrices: en el primer caso (principios en sentido estricto), se trata de determinar la prevalencia o no del principio bajo consideración en relación con otros principios eventualmente concurrentes; determinada esta prevalencia, el principio en cuestión exige un cumplimiento pleno; en el segundo caso (directrices o normas programáticas), se trata de diseñar y llevar a cabo políticas que procuren el mayor grado de satisfacción posible de los diversos objetivos, interdependientes entre sí, a los que apuntan las diversas directrices. De ahí que concluyéramos Atienza y yo en Las Piezas que "la teoría de Robert Alexy de los principios como mandatos de optimización resulta [...] distorsionadora en relación con los principios jurídicos en sentido estricto, pero perfectamente adecuada para dar cuenta de las directrices”.

En un trabajo que se publica en este mismo número de Doxa, Josep Aguiló ofrece un cuadro en el que sintetiza muy adecuadamente nuestra caracterización de la oposición entre principios en sentido estricto y directrices de la siguiente forma:

\begin{tabular}{|l|l|l|}
\hline \multicolumn{1}{|c|}{ Principios } & \multicolumn{1}{|c|}{$\begin{array}{c}\text { Principios en sentido } \\
\text { estricto }\end{array}$} & \multicolumn{1}{c|}{ Directrices } \\
\hline $\begin{array}{l}\text { Pertenecen al género normas } \\
\text { regulativas }\end{array}$ & Normas de acción & Normas de fin \\
\hline $\begin{array}{l}\text { Función directiva que } \\
\text { cumplen. }\end{array}$ & Imponen límites & Ordenan objetivos \\
\hline Medida de cumplimiento & $\begin{array}{l}\text { Cumplimiento pleno; todo } \\
\text { o nada. }\end{array}$ & $\begin{array}{l}\text { Mandatos de optimización; } \\
\text { cumplimiento en la mayor } \\
\text { medida... }\end{array}$ \\
\hline $\begin{array}{l}\text { Tipo de relación entre } \\
\text { acciones y estados de cosas. }\end{array}$ & $\begin{array}{l}\text { Vinculación conceptual o } \\
\text { intrínseca, no causal, entre } \\
\text { acciones y estados de cosas. }\end{array}$ & $\begin{array}{l}\text { Vinculación causal o } \\
\text { extrínseca, no conceptual, } \\
\text { entre acciones y estados de } \\
\text { cosas. }\end{array}$ \\
\hline $\begin{array}{l}\text { Juicios de adecuación de la } \\
\text { conducta a las normas. }\end{array}$ & $\begin{array}{l}\text { Juicio de corrección no } \\
\text { graduable }\end{array}$ & Juicio de eficacia graduable \\
\hline $\begin{array}{l}\text { Valores sustantivos que } \\
\text { incorporan }\end{array}$ & Valores últimos & Valores utilitarios \\
\hline
\end{tabular}

${ }^{8}$ M. Atienza y J. Ruiz Manero: Las piezas del Derecho, cit., p. 11. 
La mayor parte de los contenidos de estos casilleros se han visto reflejados, creo, en los párrafos que anteceden. No se ha hecho referencia hasta ahora, sin embargo, a los tipos de relación entre acciones y estados de cosas característicos de principios en sentido estricto y de las directrices ni tampoco a los valores sustantivos que incorporan unos y otras -consideración vinculada a la tesis, defendida por nosotros, de la prioridad de los principios en sentido estricto sobre las directrices. Sobre estos puntos me extenderé con cierta amplitud más adelante.

Desde la primera edición de Las Piezas, se han publicado diversos textos que han vuelto, en todos los casos de forma aguda, sobre esta crítica nuestra a Alexy y los problemas involucrados en ella. Las páginas que siguen tratan de dar cuenta y de responder a estos trabajos.

De entre ellos, el artículo de Robert Alexy “Sobre la estructura de los principios jurídicos”9 contiene una respuesta -adelantaré que, en mi opinión, no convincente- a nuestra crítica.

Posteriormente, Atienza y Alexy han vuelto sobre estos problemas en la entrevista que el primero hizo al segundo en el número 24 de $\operatorname{Doxa}^{10}$. Adelantaré que, en mi opinión, tanto lo que aquí expone Atienza (en forma de pregunta) como lo que contesta Alexy, está lastrado por el uso de malos ejemplos, de ejemplos que, a mi juicio, conducen la discusión fuera del punto y sirven para enredarla en malentendidos.

En el número anterior de Doxa, Gloria Lopera ${ }^{11}$, en un trabajo que resulta a la vez profundo y brillante, propuso una manera de entender la tesis de Alexy de los principios como mandatos de optimización a partir de la cual la divergencia entre esta tesis y lo que defendimos Atienza y yo en Las piezas sería puramente aparente o, lo que es lo mismo, meramente verbal. Nuestra posición sería perfectamente compatible con la de Alexy, tal como es reformulada por Lopera. Adelantaré que creo que, si concordamos en que la mejor interpretación de un texto es la que ofrece la mejor versión posible de lo que ese texto sostiene, la interpretación propuesta por Lopera es, sin duda, la mejor interpretación de Alexy. Pero creo también que eso no quita para que haya una diferencia importante entre las posiciones de Alexy y las nuestras, que la interpretación de Lopera difumina. Y esta diferencia acarrea

\footnotetext{
${ }^{9}$ R. Alexy: "Sobre la estructura de los principios jurídicos”, en R. Alexy: Tres escritos sobre los derechos fundamentales y la teoría de los principios, presentación y traducción de Carlos Bernal Pulido, Universidad Externado de Colombia, 2003. Publicado originalmente como “Zur Struktur der Rechtsprinzipien”, en B. Schilcher et al. (eds.): Regeln, Prinzipien und Elemente im System des Rechts, Verlag Österreich, Viena, 2000.

${ }^{10}$ M. Atienza: “Entrevista a Robert Alexy”, en Doxa, $\mathrm{n}^{\circ}$ 24, 2001.

${ }^{11}$ G. Lopera: "Los derechos fundamentales como mandatos de optimización”, en Doxa, $n^{\circ} 27,2004$.
} 
una ventaja para nuestra construcción, pues ésta posibilita dar cuenta de dos maneras diferentes en que principios de dos tipos diferentes de estructura (principios en sentido estricto y directrices) pretenden regular la conducta e incidir sobre el razonamiento práctico de sus destinatarios; la construcción de Alexy, por su parte, presenta indiferenciadamente la estructura y la manera de operar de uno y otro tipo de principios.

Finalmente, también en este mismo número de Doxa, Josep Aguiló formula, con título de apariencia inocente, “Tres preguntas sobre principios y directrices" ${ }^{2}$. Pero sus tres preguntas son capitales para cualquier teoría de los principios y una construcción que no fuera capaz de proporcionar una respuesta adecuada a las mismas debería, sólo por eso, ser abandonada o, cuando menos, reelaborada a fondo. La tesis implícita de Aguiló es que esto es precisamente lo que ocurre en nuestro caso. Supongo que no es una sorpresa para nadie si adelanto que, a mi juicio, no tiene razón.

\section{Una réplica de Alexy}

En su trabajo “Sobre la estructura de los principios jurídicos” Robert Alexy señala acertadamente que, de acuerdo con nuestra reconstrucción de los principios en sentido estricto, éstos "no deben cumplirse en diferente grado, sino que sólo pueden seguirse o no seguirse" ${ }^{13}$ y también que lo esencial en nuestra reconstrucción es la cláusula que, de acuerdo con lo que antes veíamos, permite pasar del debe prima facie al debe concluyente. Escribe, en relación con el mismo ejemplo que nosotros utilizamos, citando el texto de la edición inglesa de Las Piezas, que "la parte decisiva de esta reconstrucción del artículo 14 de la Constitución española es la cláusula 'and there is no countervailing principle of higher weight in the case at hand', que no se encuentra en el texto constitucional" ${ }^{14}$. A partir de aquí, Alexy concuerda con nosotros en que una norma como el artículo 14, entendida como provista de semejante cláusula, "sin duda alguna [...] no puede cumplirse en diferente grado”. Pero, inmediatamente a continuación, añade: “Sin embargo, su propiedad de poder ser sólo cumplida o incumplida, es trivial. Cada principio puede asimilarse a una norma todo-o-nada mediante una cláusula general de reserva como aquella que establece: ' $\mathrm{y}$ cuando otro principio contrario con mayor peso no ordene otra cosa’ [...] Atienza y Ruiz Manero están en lo cierto cuando afirman que el artículo 14 de la Constitución española, en la reconstrucción emprendida por ellos, establece una consecuencia jurídica

\footnotetext{
12 J. Aguiló Regla: “Tres preguntas sobre principios y directrices”, en este número de Doxa.

${ }^{13}$ R. Alexy: “Sobre la estructura de los principios jurídicos”, cit., p. 119.

${ }^{14}$ Ibid., p. 120.
} 
definitiva. No obstante, esto se deriva únicamente de la cláusula no escrita introducida por ellos”15. La cuestión es si esa cláusula no escrita introducida por nosotros da cuenta o no adecuadamente de la manera cómo los principios se aplican a los casos y si este dar cuenta es, o no, trivial. En cuanto a lo primero, Alexy no parece negar la virtualidad de la cláusula, porque escribe que, de acuerdo con ella, "todo desemboca en una ponderación”16. Por supuesto: pues ponderación es precisamente el nombre de la operación destinada a determinar el peso relativo, en relación con las propiedades de un cierto caso, de diversos principios en concurrencia. Pero, a partir de ahí, y sin más base que la expuesta, Alexy se limita a enunciar aquello que, al constituir el objeto de la controversia, debería demostrar: "Hay que tener en cuenta que los objetos de la ponderación sólo pueden reconstruirse de manera racional como principios entendidos en el sentido de la tesis de la optimización. [...] En cuanto principios, en el sentido de mandatos de opti-

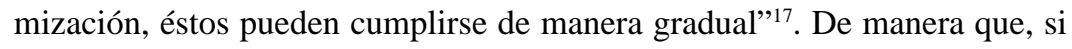
resumimos lo dicho por Alexy, resulta: 1) que éste acepta que, de acuerdo con nuestra reconstrucción, de los principios se derivan mandatos definitivos que sólo pueden cumplirse o incumplirse, sin posibilidad de gradualidad en el cumplimiento; 2) pero afirma que ésta es una tesis trivial; 3) y es trivial, a juicio de Alexy, porque depende de una cláusula no hace otra cosa sino indicar que de los principios sólo se derivan deberes concluyentes tras la ponderación; y 4) sin argumentos adicionales, afirma que para reconstruir adecuadamente los objetos de la ponderación hay que aceptar la tesis de los mandatos de optimización y de la posibilidad de cumplimiento gradual. Pero esta es precisamente la cuestión bajo disputa y, por ello, la argumentación de Alexy parece contener una petición de principio.

\section{Los malos ejemplos de Atienza y Alexy}

En el número 24 de Doxa se publicó una entrevista a Robert Alexy realizada por Manuel Atienza, que resulta de un interés notable en relación con diversos aspectos del pensamiento de Alexy. Su examen habrá de limitarse aquí, sin embargo, a las cuestiones de teoría de los principios respecto de las cuales se produce la divergencia entre las posiciones de Alexy y las que sostuvimos conjuntamente Atienza y yo mismo. A este respecto, Atienza introduce una pregunta en la que alude a algunos rasgos de la teoría de los principios defendida por nosotros, y especialmente a las tesis de la prioridad de los principios en sentido estricto sobre las directrices y del cumplimiento pleno,

\footnotetext{
${ }^{15}$ Ibid., pp. 120-1.

${ }^{16}$ Ibid., p. 122.

${ }^{17}$ Ibid., p. 122.
} 
sin posibilidad de gradualidad, exigido por los primeros. Y, en este sentido, escribe: "la aplicación de las directrices (por ejemplo, la preservación del medio) supone un aspecto de gradualidad que parecería raro predicar de otro tipo de principios (la dignidad humana no parece ser una cuestión de más o menos)"18. Este señalar a la dignidad humana como ejemplo de principio en sentido estricto y, como tal, no susceptible de modalidades graduables de cumplimiento, resulta, en mi opinión, desafortunado porque la dignidad humana se halla en un nivel justificativo superior al de los casos centrales de principios jurídicos en sentido estricto y ello hace que sus exigencias operen de distinta manera a como operan los que consideramos como casos centrales de principios. Me refiero a lo siguiente: el principio de dignidad humana no está sujeto a ponderación en virtud de la cual pueda verse desplazado, en el caso que se considere, por algún otro principio concurrente. El deber de tratar a cualquiera de acuerdo con su dignidad humana es así, no sólo un deber de cumplimiento no graduable -como indica, en mi opinión con toda razón, Atienza- sino también un deber que resulta concluyente sin necesidad de ponderación, esto es un deber no sujeto a excepciones. Dicho de otra forma: en los casos centrales de lo que llamamos principios jurídicos en sentido estricto -como, por ejemplo, el principio de prohibición de discriminación entre personas por su diferente adscripción religiosa, al que se aludía antes, o el principio de respeto a la libertad de expresión- estos contienen un deber prima facie que sólo deviene deber concluyente tras haber determinado, por medio de la ponderación, que ese principio no se ve desplazado, en el caso de que se trate, por otro principio que tenga, en relación con ese caso, un mayor peso. Y es por ello por lo que resulta completamente natural hablar de casos justificados de discriminación a quienes sostienen ciertas creencias religiosas o de casos justificados de interferencia en la libertad de expresión (porque en ellos prevalezca la protección del honor, o de la intimidad, etc.). Pero no ocurre lo mismo con la dignidad humana: la expresión "trato justificado no acorde con la dignidad humana” es una expresión autocontradictoria; las exigencias de la dignidad humana no se ponderan ni ceden en ningún caso frente a otras exigencias que resulten concurrentes. El deber de respeto a la dignidad humana es, así, absoluto.

Esto es lo que explica que, en su respuesta, Alexy pueda impugnar, a mi juicio con razón, la pertinencia del ejemplo del principio de la dignidad humana en relación con los problemas que plantean los casos centrales de principios. Escribe así: "La dignidad humana tiene, como todos los derechos que están tanto en la bóveda como en el fundamento del edificio, una estructura distinta a la de los otros derechos fundamentales. En los derechos

${ }^{18}$ M. Atienza: “Entrevista a Robert Alexy”, cit., pp. 676-7. 
fundamentales normales una intromisión no significa todavía una lesión. Una intromisión se convierte en una lesión cuando no está justificada. La dignidad humana carece de esa estructura de intromisión/límites. En ese sentido tiene un carácter de regla. Toda intromisión en la dignidad humana significa su lesión” ${ }^{19}$.

Pero si Alexy parece tener razón en que el principio de dignidad no es, por las razones expuestas, un buen ejemplo de principio, el ejemplo del que él se sirve para combatir la tesis según la cual los principios en sentido estricto prevalecen siempre frente a las directrices -el derecho de propiedadtampoco es un ejemplo adecuado; y no lo es porque se basa, a mi juicio, en una asimilación apresurada, y por ello, no justificada, entre principios en sentido estricto y derechos individuales. En efecto, Alexy parece suponer que nuestra distinción entre principios en sentido estricto y directrices o normas programáticas es completamente coextensiva con la distinción “entre principios que tienen como objeto derechos individuales y principios cuyo objeto son bienes colectivos”20. Y esto no es así, por la razón de que la adscripción de derechos individuales es una técnica que puede emplearse tanto como plasmación de principios en sentido estricto como en cuanto instrumento para el logro de objetivos colectivos (o para alguna combinación de ambas cosas) ${ }^{21}$. De forma que, de entre los derechos individuales debemos distinguir entre derechos que corresponden a principios en sentido estricto (que serían, en nuestra concepción, derechos provistos de justificaciones últimas), derechos que se configuran para contribuir a implementar directrices (que, para esta concepción, serían derechos provistos de justificaciones utilitarias) y derechos que en parte corresponden a principios en sentido estricto y en parte se orientan a implementar directrices (que serían derechos provistos de justificaciones mixtas).${ }^{22}$ Corresponden a principios en sentido estricto (o, lo que es lo mismo, están provistos de justificaciones últimas) aquellos derechos que se orientan a la protección de bienes o intereses que se consideran dignos de igual protección para todos y cada uno de los seres

19 "Entrevista a Robert Alexy”, cit., p. 678.

20 "Entrevista a Robert Alexy”, cit., p. 677.

${ }^{21}$ En sentido similar a lo aquí sostenido, sin embargo, y en contraste con lo que en esta entrevista manifiesta, véase R. Alexy: “Individual Rights and Collective Goods”, en donde éste, de forma enteramente correcta en mi opinión, escribe que "detrás de un derecho individual puede existir un haz de razones muy diferentes y diferentes derechos pueden apoyarse en razones muy diferentes [...]Es posible considerar como razones para los derechos no sólo bienes individuales tales como los intereses de los titulares de los derechos de que se trate o su libre voluntad, sino también bienes colectivos” (R. Alexy: "Individual Rights and Collective Goods, en C. S. Nino -ed.- Rights, Darmouth, Aldershot, 1992, p.164).

${ }^{22}$ Sigo aquí lo expuesto por M. Atienza y yo mismo en Ilícitos atípicos, cit., pp. 49 ss. 
humanos. Se trata de derechos que se adscriben universalmente, esto es, derechos de los que son titulares todos y cada uno de los individuos y en los que los bienes o intereses que se trata de proteger o promover son bienes 0 intereses del propio titular del derecho. Un ejemplo de este tipo de derechos sería el derecho de todos a no ser "sometidos a torturas ni a penas o tratos inhumanos o degradantes” (art. 15 CE). Corresponden, por el contrario, a directrices (o, lo que es lo mismo, están provistos de justificaciones utilitarias) aquellos derechos que se orientan a la protección o promoción de bienes o intereses colectivos, de bienes o intereses distintos, pues, de los del propio titular del derecho. Un ejemplo de derecho de este tipo es el derecho "a la cláusula de conciencia y al secreto profesional” de que gozan, de acuerdo con el art. 20.1 CE, los individuos de una cierta clase, los periodistas. La justificación de estos derechos se halla en que ellos sirven para maximizar un bien colectivo y público, el de la información públicamente disponible. Como ha escrito Francisco Laporta, es para "incentivar el fluido de información en una sociedad deliberante” para lo que se protegen mediante el secreto las fuentes de la información; algo análogo ocurre con la cláusula de conciencia: con ella no se trata de proteger la conciencia del periodista-que no se considera que tenga, como tal, un valor superior a la conciencia de un empleado de pajarería, trabajador de la construcción o profesor de universidad- sino el evitar, dicho de nuevo con palabras de Laporta, que "algunas informaciones u opiniones sobre aspectos de la realidad, cuyo vehículo es un informador o grupo de informadores, dejen de acceder al ámbito del discurso público como consecuencia de un condicionamiento económico de carácter personal”23.

Por lo que se refiere al derecho de propiedad éste es, claramente, el caso paradigmático de derecho provisto de una justificación mixta. Pues resulta claro que en la configuración de ese derecho intervienen tanto consideraciones de principio o justificaciones últimas -consideraciones que exigen que ese derecho se adscriba universalmente- como consideraciones en términos de directrices -consideraciones que posibilitan una distribución desigualitaria de ese derecho. La justificación en términos últimos o de principio del derecho de propiedad se halla en la conexión entre ese derecho y la autonomía personal: un cierto quantum de propiedad -esto es, de control individual de recursos- es condición necesaria para la elección y materialización de cualesquiera planes de vida. Lo que esta justificación de principio de la propiedad exige es meramente la adscripción a todos y cada uno del control individual sobre el quantum de recursos necesarios

${ }^{23}$ F. J. Laporta: “El derecho a informar y sus enemigos”, en Claves de Razón Práctica, $\mathrm{n}^{\circ}$ 72, 1997, pp. 16-7. 
para poder llevar a cabo una existencia autónoma. Pero en la configuración concreta del derecho de propiedad (esto es, en el sistema de reglas en que consiste esa configuración) cuentan, además de esta razón de principio, razones de directriz -justificaciones utilitarias-, que pueden incidir a la hora de diseñar esa configuración concreta de forma que resulte funcional para muy diversos objetivos colectivos. Entre ellos, cabe mencionar, de un lado, la maximización de la riqueza social, que explica que la configuración de la propiedad privada sea más amplia (en cuanto a los bienes susceptibles de devenir propiedad privada de alguien, en cuanto a las facultades del propietario - por ejemplo, por lo que hace a la transmisibilidad hereditaria- y en cuanto a la posibilidad de acumulación de propiedad) de lo que exigiría la mera razón de la autonomía. Y, de otro, un amplio listado de objetivos heterogéneos (como, por limitarnos a algunos que aparecen mencionados en una Constitución como la española, el logro de una distribución de la renta personal y regional más equitativa, la modernización y desarrollo de todos los sectores económicos, el acceso al trabajo, la conservación del patrimonio histórico, cultural y artístico, el acceso a una vivienda digna y adecuada, la protección de los consumidores y usuarios, la protección de la familia, etc.) que pueden operar como razones para acotar de una u otra manera -en muchas ocasiones, según la naturaleza de los bienes- el alcance de las posiciones normativas que las reglas configuradoras de la propiedad asignan al propietario.

Alexy, como he indicado antes, asimila, de un lado, principios en sentido estricto con "principios que tienen como objeto derechos individuales" y, de otro, directrices con "principios cuyo objeto son bienes colectivos”. Y, en relación con el derecho de propiedad, presenta las cosas como si el derecho de propiedad fuera el correlato de un principio en sentido estricto, de forma que las limitaciones del derecho de propiedad (en atención, por ejemplo, a la protección del medio) aparecen como otros tantos triunfos de directrices frente a ese principio en sentido estricto. De esta forma, no habría diferencia entre las colisiones entre principios en sentido estricto y las colisiones entre principios y directrices y resultaría falsa nuestra tesis de la prioridad de los principios en sentido estricto sobre las directrices. Escribe, así, que "el fundamento jurídico para una intromisión tiene que ser tanto más fuerte, cuanto más intensa sea la intromisión. Esto vale tanto para la colisión entre derechos individuales, como para la colisión entre derechos individuales y bienes colectivos. Para justificar una débil intromisión en la propiedad basta con que por medio de ella se produzca una mejora del medio ambiente relativamente poco importante. Una intromisión muy grave en la propiedad, por el contrario, sólo es lícita si es de una gran importancia para la protección 
del medio"24. Pero, tal como hemos visto, en derechos como el de propiedad la persecución de bienes colectivos no opera como límite de un derecho que, en cuanto tal, apareciera como ilimitado, sino como fundamento justificativo de la propia configuración del derecho. De forma que el que la propiedad privada no sea un derecho ilimitado no muestra que, en ocasiones, haya directrices que prevalezcan sobre principios en sentido estricto, sino que principios en sentido estricto y directrices inciden sobre la configuración en forma de reglas del derecho de propiedad. Los primeros -el principio de autonomía- exigiendo que en relación con un cierto quantum de bienes sea accesible a todos un haz de posiciones normativas que sea recognoscible como lo que tradicionalmente se ha llamado propiedad privada; las segundas -prácticamente todas las directrices- contribuyendo a diseñar el sistema de reglas constitutivo de ese haz de posiciones normativas de forma que resulte funcional para el logro de los más diversos objetivos colectivos.

\section{Dos sentidos de gradualidad}

En el número 27 de Doxa se publicó el trabajo de Gloria Lopera "Los derechos fundamentales como mandatos de optimización”, uno de los trabajos más penetrantes sobre teoría de los principios que he podido leer en los últimos años. No voy a entrar aquí en sus diversos meandros, llenos todos ellos de sugerencias que, cuanto menos, resultan dignas de ser discutidas, sino solamente en la manera en cómo presenta la tesis de Alexy de los principios como mandatos de optimización. De acuerdo con Lopera, esta tesis de Alexy puede -debe- entenderse de acuerdo con una distinción que hace que la crítica a la que la sometimos Atienza y yo mismo resulte completamente irrelevante. Pues, escribe Lopera, la idea

"de los principios como mandatos de optimización, normas que ordenan que algo se realice 'en la mayor medida posible' [...] puede ser entendida en dos sentidos: 1) como intensidad de la aplicación: predicable en el caso de aquellas normas que admiten un cumplimiento gradual o aproximativo (en una escala de 0 a $100 \%$ ) como sucede con la mayoría de los principios que prescriben la obtención de un estado de cosas (las directrices, en el lenguaje de Atienza y Ruiz Manero): garantizar un medio ambiente sano, el acceso a una vivienda digna, la protección de los consumidores, etc.; 2) como frecuencia de la aplicación. Tal es el sentido que adquiere la exigencia de cumplimiento 'en la mayor medida posible' respecto de aquellos principios cuyo objeto no admite una realización aproximativa ('no matar', 'no discriminar'), caso en el cual la exigencia que incorpora el mandato de optimización es una exigencia de cumplimiento 'en el mayor número de ocasiones posible’. En este sentido cabe entender la graduabilidad incorporada a la noción de mandato de optimización en el caso de aquellos

24 “Entrevista a Robert Alexy”, cit., pp. 677-8. 
principios que prescriben la realización de acciones. De este modo -concluye Lopera-, la caracterización de los principios como mandatos de optimización sería predicable tanto de las directrices (prescriben estados de cosas) como de los principios en sentido estricto (prescriben acciones)".

Realmente, no parece haber nada que objetar, desde nuestra perspectiva, a lo sostenido por Lopera. Y ello porque lo que hace Lopera es completar la teoría de los principios de Alexy con la distinción entre principios en sentido estricto y directrices en los términos en los que nosotros la trazamos, de forma que la tesis del mandato de optimización se entienda de forma que resulte compatible con nuestra tesis del cumplimiento pleno en el caso de los principios en sentido estricto y graduable en el caso de las directrices. Queda así aceptado que principios en sentido estricto y directrices son tipos diferentes de principios que tienen una estructura diferente y que guían la conducta de forma asimismo diferente. Queda, pues, aceptado, lo esencial de las tesis que Atienza y yo oponíamos a la concepción de Alexy. Queda tan sólo, en relación con la integridad de nuestras tesis, la conexión de los principios en sentido estricto con valores últimos y de las directrices con valores utilitarios, por un lado, y por otro, la tesis según la cual los principios en sentido estricto prevalecen en todo caso definitivamente sobre las directrices (y no tienen sólo una mera prevalencia prima facie). Pero de estas cuestiones me ocuparé a propósito de las cuestiones planteadas en el texto de Aguiló.

\section{Tres preguntas no inocentes}

\subsection{Relaciones conceptuales y relaciones causales; principios en sentido estricto y directrices.}

Aunque Aguiló titula su texto “Tres preguntas sobre principios y directrices”, de hecho pone en cuestión bastante más de tres aspectos parciales de lo sostenido al respecto por Atienza y yo. El primer punto a que hace referencia críticamente Aguiló es el de la distinción entre relaciones conceptuales y relaciones causales entre estados de cosas y acciones. Debo decir que, en este punto, Atienza y yo no hicimos otra cosa que seguir estrictamente a von Wright. La distinción entre relaciones conceptuales y causales entre acciones y estados de cosas corresponde exactamente a la que media entre resultado y consecuencia de las acciones. El resultado de una acción guarda con esa acción, dice von Wright, una relación intrínseca o conceptual, mientras que las consecuencias de una acción guardan con esa acción una relación causal ${ }^{25}$. Dicho de otra forma: si alguien afirma que se

${ }^{25}$ G.H. von Wright: Norma y acción, cit., pp. 56-7: “[...] el nexo entre el acto y su resultado es intrínseco. El acto no puede verdaderamente ser descrito como un acto de la categoría en cuestión, a menos que efectúe un cambio o termine en un estado de cosas de la especie en 
ha realizado una acción, pero que no se ha producido su resultado, incurre en un error analítico o conceptual: su proposición es autocontradictoria; por el contrario, las proposiciones que afirman que se han seguido tales o cuales consecuencias de una acción, al aludir a nexos causales, son verdaderas o falsas empíricamente. Por ejemplo, si afirmamos que Juan ha matado a Pedro, pero que Pedro no ha resultado muerto emitimos un enunciado autocontradictorio, que resulta falso en virtud del significado de sus términos; si afirmamos que, como consecuencia de la realización de esa acción, la viuda de Pedro está muy afligida, o muy alegre, emitimos un enunciado que resultará verdadero o falso según sea, en efecto, el estado de ánimo de la viuda de Pedro. Pero supongamos que, en efecto, la viuda de Pedro está afligida: en tal caso, podemos afirmar con verdad que matar a Pedro ha sido un medio para entristecer a su esposa (tras la realización de la acción, viuda) pero nunca que matar a Pedro sea una "forma” de entristecer a su esposa, si es que, como es usual en la literatura al respecto, el término "forma” lo reservamos para relaciones conceptuales y no causales. Esto es, "matar con veneno" y "matar con puñal” son, en efecto, "formas” de matar; pero "suministrar veneno" o "apuñalar” no son "formas” de matar, sino, en su caso, meros "medios” para ello: la proposición “Juan mató con veneno [o con puñal] a Pedro, pero Pedro no resultó muerto” es autocontradictoria, pero la proposición “Juan suministró veneno [o apuñaló] a Pedro, pero Pedro no resultó muerto” es sólo empíricamente verdadera, o falsa. Es por ello por lo que Aguiló no tiene razón cuando escribe que

"tanto en el caso de la directriz como en el de los principios la relaciones entre acciones y estado de cosas es primero causal y como consecuencia de ello también conceptual. En el caso de la directriz, la relación entre la acción que se realiza (por ejemplo, imponer las pruebas de detección del virus [del SIDA]) y el estado de cosas ordenado o debido (que la salud de los ciudadanos esté protegida) tiene que ser causal. La acción tiene que ser un medio para el fin. Una vea afirmada esta relación causal, podemos establecer una relación conceptual entre la acción de imponer las pruebas de detección del virus (la acción) y la

\footnotetext{
cuestión, que llamaremos su resultado. Un acto no puede verdaderamente ser llamado un acto de abrir la ventana, a menos que termine (resulte) en que la ventana esté abierta -por lo menos durante un corto tiempo- [...] Cuando el mundo cambia en un determinado respecto puede suceder que, por virtud de la llamada necesidad causal o natural, también llegue a transformarse en otro determinado respecto. Entonces decimos que la segunda transformación es una consecuencia de la primera. Si la primera transformación se efectúa a través de una acción, es el resultado de un acto; entonces la segunda es una consecuencia de la acción, una consecuencia de ese acto [...] Que una determinada transformación sea causa de que otra determinada transformación tenga lugar o no, normalmente dependerá de la presencia o ausencia de un cierto número de otras características del mundo, además de los estados asociados con las dos transformaciones mismas [...] A diferencia de la relación entre un acto y su resultado, la relación entre un acto y sus consecuencias es extrínseca (causal)”.
} 
protección de la salud de los ciudadanos (el estado de cosas) y, en consecuencia, afirmar que imponer las pruebas de detección del virus es una 'forma' (junto con otras posibles) de proteger la salud [...]. Me parece que la cosa no es distinta en el caso de los principios en sentido estricto (o en las normas de acción en general). Sólo una vez que hemos determinado la relación causal, admitimos la relación conceptual entre lo que se hace y el estado de cosas debido [...]. Empecemos con un ejemplo sencillo. Si tomamos la prohibición de matar como ejemplo de norma de acción, entonces todas aquellas acciones que causalmente provocan el resultado muerte, en efecto las consideramos 'formas de matar': disparar, apuñalar, envenenar, etc. las consideramos formas de matar. Pero lo importante es que las consideramos así porque afirmamos la relación causal”

Pues bien: no. Cuando afirmamos la existencia de una relación causal entre una cierta acción y un cierto estado de cosas, afirmamos sólo eso: la existencia de una relación causal. A partir de ahí, como hemos visto, no podemos afirmar legítimamente la existencia de relación conceptual alguna. “Disparar”, “apuñalar”, “envenenar” no son “formas” de matar porque ninguna de esas acciones implica conceptualmente el resultado "muerte”.

Todo esto no tiene más importancia que la de aclarar la distinción entre relaciones conceptuales y relaciones causales entre acciones y estados de cosas que Aguiló ha entendido, en mi opinión, de forma inadecuada. En todo caso, la distinción, entendida como se acaba de presentar, era vinculada por Atienza y yo a la distinción entre principios en sentido estricto y directrices, en el sentido de que, en el caso de los principios en sentido estricto, la relación relevante entre acciones y estados de cosas es la relación analítica o conceptual, mientras que, en el caso de las directrices, la relación relevante es la causal. Ilustremos esto con un par de ejemplos. Pensemos, como ejemplo de principio en sentido estricto, en el principio de libertad de expresión del art. 20 a) CE, contemplado como principio que ordena, prima facie, abstenerse de interferir en la expresión y difusión de los pensamientos, ideas y opiniones ${ }^{26}$. La pregunta relevante en relación con la acción es aquí la de ¿en qué consiste “interferir”? Y una buena respuesta podría ser, de entrada, que “interferir” consiste en impedir, en prohibir o en sancionar actos de expresión o difusión de pensamientos, ideas u opiniones. "Impedir”, "prohibir” o "sancionar" son formas de interferir, no medios para la interferencia: "impedir”, "prohibir” o "sancionar” implican conceptualmente "interferir”; aquí no hay ninguna relación causal involucrada. Las cosas son distintas si pasamos a las directrices. Pensemos como

\footnotetext{
${ }^{26}$ Sobre que las libertades constitucionales implican prohibiciones de interferencia, pero no pueden reducirse a ellas, véase el apéndice al capítulo 3 de Las Piezas y también M. Atienza y J. Ruiz Manero: "Permissions, Principles and Rights. A Paper on Statements Expressing Constitutional Liberties, en Ratio Iuris, vol 9, n 3, 1996.
} 
ejemplo en el deber de los poderes públicos de "promover las condiciones para que la libertad y la igualdad del individuo y de los grupos en que se integra sean reales y efectivas” $y$, a los fines de paralelismo en el ejemplo, entendámoslo como referido a la libertad de expresión. Aquí, desde luego, cabe como relevante la pregunta de ¿en qué consiste que la libertad de expresión sea real y efectiva? Y la respuesta puede ser que ello consiste en que todos los individuos y grupos puedan (en el sentido de capacidad y no meramente en el de permisión) efectivamente ejercer la libertad de expresión. Pero, junto con esa pregunta, surge otra pregunta relevante, la pregunta de ¿cómo se puede lograr ese estado de cosas en el que todos los individuos y grupos pueden efectivamente ejercer la libertad de expresión? Y aquí las respuestas aluden ya a acciones muy heterogéneas que se consideran o no medios idóneos para ello: por ejemplo, y por no alargar excesivamente el listado, adoptar medidas que contribuyan a incrementar el nivel cultural de la población (o de los segmentos con menor nivel educativo); facilitar el acceso a la propiedad de periódicos o de emisoras de radio a asociaciones representativas de grupos numerosos cuya ubicación social sea más bien subalterna (como sindicatos, asociaciones vecinales, juveniles, de mujeres o de minorías étnicas, etc.), utilizar el sistema escolar para inculcar en los jóvenes el hábito de leer periódicos y discutir pertinentemente lo que leen, y un sinnúmero de acciones más que podamos imaginar. Todas estas acciones son, en su caso, medios de lograr el estado de cosas ordenado, mantienen con él una relación causal y no conceptual: no hay nada conceptualmente incorrecto en decir que se realizó alguna (o varias) de estas acciones y, sin embargo, no se logró el estado de cosas pretendido, o se logró en una medida muy pequeña (o muy grande, o extraordinaria, etc.). Y, de otro lado, que estas acciones u otras que pudieran imaginarse sean, efectivamente, medios idóneos para hacer real y efectiva la libertad de expresión es, con seguridad, asunto altamente controvertible, como, aun aceptando que lo sean, es también altamente controvertible que deban emplearse precisamente estas medidas y no otras (de las que pueda pensarse que son más eficaces o de menor coste). Y es que, en efecto, la concreción de fines y de sus medios de realización que el cumplimiento de directrices entraña implica necesariamente, de un lado, una cierta priorización (desde luego, no lexicográfica) de los diversos fines ordenados (priorización que no se desprende del propio sistema jurídico y a la que, por ello, podrían oponerse otras priorizaciones asimismo admisibles) y de otro, juicios sobre relaciones medio-fin (cuya verdad no viene determinada por el sistema jurídico y a los que, por ello, podrían oponerse en la mayor parte de las ocasiones, otros juicios sobre tales relaciones igualmente plausibles 
e incompatibles con los anteriores) ${ }^{27}$. De ahí que el establecimiento de estas priorizaciones y la asunción de estos juicios sobre relaciones medio-fin sea asunto centralmente encomendado a los órganos de deliberación y decisión democráticamente legitimados.

Pero, en todo caso, la distinción entre relaciones conceptuales y relaciones causales entre acciones y estados de cosas no es, como sugiere Aguiló, "ideológica” ni tiene como función el llevar a cabo ninguna "ocultación” sino que, bien al contrario y adecuadamente entendida, arroja, creo, una luz importante sobre dos maneras distintas que tienen las normas de guiar la conducta, posibilita entender por qué la aplicación de directrices supone discrecionalidad y la de principios en sentido estricto no la supone y también por qué, en materia de directrices, la función de los tribunales no va, en los casos centrales, más allá de controlar que los órganos democráticamente legitimados no han desbordado los márgenes de esa discrecionalidad.

Sin embargo, si Aguiló impugna la distinción entre relaciones conceptuales y relaciones causales entre acciones y estados de cosas es, básicamente, para prepararse el terreno para atacar la tesis, defendida en Las Piezas, según la cual los principios en sentido estricto prevalecen siempre sobre las directrices: "en mi opinión -escribe- la insistencia en la relación conceptual [...] frente a la causal es en el mejor de los casos una necesidad interna de la propia teoría para poder seguir sosteniendo que los principios en sentido estricto prevalecen siempre sobre las directrices”. He argumentado hasta ahora por qué esa distinción entre relaciones conceptuales y relaciones causales es, a mi juicio, clarificadora, pero de lo que se trata ahora es de abordar la crítica de Aguiló a la tesis de la prevalencia de principios sobre directrices. Aguiló pone en cuestión dicha tesis con la ayuda de una argumentación que podríamos llamar “de sentido común”, de forma que, después de haber acompañado a Aguiló en su argumentación, uno puede quedarse con la impresión de que sólo un fanático principialista, por completo insensible a los costes, podría seguir sosteniendo dicha prevalencia. Veámoslo. Aguiló empieza por relatar la respuesta que, en una conferencia a la que asistió, daba la conferenciante a la cuestión de si cabe, en nuestro Derecho, establecer la obligatoriedad de las pruebas de detección del virus del sida. La conferenciante, nos dice, admitía que establecer dicha obligatoriedad podría ser muy eficaz para la protección de la salud (fin cuya persecución viene ordenada por el art. $43 \mathrm{CE}$ ), pero sostenía que el establecimiento de dicha obligatoriedad estaba excluido en nuestro Derecho "porque entraba en contradicción con los principios/derechos a la dignidad (art. 10), a la integridad física y moral (art. 15) y a la intimidad personal (derecho a excluir a los

${ }^{27}$ Véase Las piezas, $2^{\text {a }}$ edición, cit., pp. 37-38. 
demás del conocimiento de aspectos de la propia persona) (art. 18)”. De ahí, sigue relatando Aguiló, la conferenciante “concluía que conforme a nuestro ordenamiento las pruebas de detección del sida siempre deben ser voluntarias y requieren consentimiento libre [...] las pruebas de detección del virus no pueden imponerse a los pacientes ni a los profesionales sanitarios”. A partir de aquí, Aguiló propone un "imaginemos que" que concluye en la descalificación de nuestra teoría, por cuanto, de acuerdo con su relato, ésta desembocaría, o bien en consecuencias fanáticas que nadie razonable estaría dispuesto a suscribir, bien en una construcción cuya artificiosidad salta a la vista y que no tendría más finalidad que tratar de salvar la teoría eludiendo al tiempo la carga del fanatismo. Permítaseme en este punto citar a Aguiló con cierta extensión:

"Imaginemos por un momento que la evolución de la infección fuera muy negativa y que, en consecuencia, el nivel de contagios se disparara; es decir, imaginemos que empieza a generarse la urgencia de proceder a un control más efectivo de la enfermedad. Imaginemos también que se produce un avance tal en las técnicas de detección de la enfermedad que permite que en lugar de tener que extraer, por ejemplo, $5 \mathrm{ml}$ de sangre fuera suficiente una gota de la yema de un dedo. Y finalmente supongamos que dados todos estos cambios pensásemos que el control de la enfermedad bien merece este ‘pequeño’ sacrificio. ¿Cuál sería la forma correcta de describir dicho cambio en relación con el derecho a la integridad física de las personas? Una primera alternativa consiste en decir que mientras que extraer $5 \mathrm{ml}$ de sangre atenta contra la integridad física de las personas (es una forma de lesionar la integridad física), la extracción de una gota de sangre, no. Esta sería la forma de describir el cambio que se sigue de la presentación de Atienza y Ruiz Manero. La evolución de la infección no sería relevante, porque la protección de la salud (valor utilitario) no puede balancearse (sopesarse) con la integridad física (valor último). El cambio relevante tiene que ver sólo con la modificación de las técnicas de detección de la enfermedad. Otra descripción posible consiste en balancear el estado de la evolución de la infección con los diferentes costes que para la integridad física de las personas tienen las diferentes pruebas de detección de la enfermedad. Así, dado el diferente coste que para la integridad física tienen las diferentes pruebas, justificar unas y no otras dado un cierto estado de evolución de la enfermedad”.

De acuerdo, pues, con Aguiló, la eventual obligatoriedad de las pruebas de detección del sida entraría en contradicción con los principios/derechos a la dignidad, a la integridad física y a la intimidad. Como nosotros sostenemos la prevalencia de los principios en sentido estricto sobre las directrices, en el caso de que se dispararan las cifras de contagio de esta enfermedad, nos veríamos obligados a escoger una de estas dos alternativas: o bien seguir afirmando que, sean cuales sean los costes, la obligatoriedad de las pruebas de detección de la enfermedad debe considerarse prohibida en nuestro Derecho por entrar en contradicción con principios del mismo o bien, utilizando el resquicio de que ha habido un avance en las técnicas 
de detección, afirmar que, mientras que la extracción de 5 ml de sangre sí atenta contra estos principios (y en concreto contra la integridad física), la extracción de una sola gota de sangre no lo hace. Esta última tesis -de la que Aguiló afirma que, como forma de describir el cambio, "se sigue de la presentación de Atienza y Ruiz Manero”- en mi opinión es altamente artificiosa y, desde luego, no la hago mía en modo alguno. Por qué diablos piensa Aguiló que "se sigue" de lo que hemos sostenido Atienza y yo es para mí un completo misterio. Y, desde luego, si nuestra teoría tuviera que incurrir en artificiosidades de este tipo para evitar la conclusión fanática de que nunca, sean cuales sean las circunstancias, puede considerarse justificada en nuestro Derecho la imposición obligatoria de pruebas de detección del sida, si fueran así las cosas, digo, nuestra teoría debería, desde luego, ser inmediatamente abandonada. Pero las cosas no son, naturalmente, así. Y ello porque lo que, en mi opinión, debe rechazarse es el punto de partida que Aguiló nos atribuye sin vacilar, a saber, que hay razones de principio que vedarían, en todo caso, la imposición de la obligatoriedad de las pruebas de detección del sida. Estas razones de principio se referirían, según dice Aguiló al inicio de su exposición del asunto, a la dignidad, a la integridad física y a la intimidad. De la dignidad, en todo caso, no vuelve a hablar posteriormente y dado que se suele considerar que el derecho a la intimidad constituye una concreción de exigencias derivadas de la dignidad, me referiré únicamente al derecho a la integridad física y al derecho a la intimidad como posibles razones de principio en contra del establecimiento de la obligatoriedad de las pruebas de detección del sida. Y lo primero que hay que decir a este respecto es que Aguiló no ofrece una sola razón por la que haya que considerar a los derechos a la integridad física y a la intimidad como constitutivos de razones de principio en contra de tal posibilidad. Empecemos por el derecho a la integridad física: sólo se me ocurre como explicación para considerar que el derecho a la integridad física impide la obligatoriedad de pruebas que requieran de extracciones de sangre (sea la cantidad de ésta $5 \mathrm{ml}$ o una gota) un entendimiento radicalmente literal de lo que significa "integridad física”, de forma que se pasa de la consideración usual de que el derecho a la integridad física prohíbe privar a una persona contra su voluntad de órganos o miembros de su cuerpo (lo que tiene relevancia, por ejemplo, para la ética de los trasplantes), a considerar que tal derecho prohíbe privar a una persona contra su voluntad de cualquier elemento de su cuerpo, por ejemplo, de $5 \mathrm{ml}$ de su sangre, privación de la que no se deriva ningún cambio perceptible en la vida ulterior de la persona. Pero este entendimiento radicalmente literal de lo que significa “integridad física” vuelve imposible, a mi juicio, integrar el "derecho a la integridad física”, así entendido, en alguna construcción justificativa acep- 
table. En cualquier construcción de este género, me parece, el alcance del derecho a la integridad física ha de depender de las razones que respaldan a ese derecho. Y no se ven razones para un derecho -que, como derecho fundamental, implica la acotación de un espacio de indisponibilidad para el legislador-, que proteja frente a la privación de cualquier elemento corporal (¿también de la fracción del cabello o de las uñas que solemos cortar?) aun si éste resulta irrelevante para la vida ulterior de la persona. Si hay razones de principio en contra de la obligatoriedad de las analíticas de sangre, éstas no se encuentran, pues, de ningún modo, me parece, en el derecho a la integridad física.

El derecho a la intimidad parece constituir, de entrada, un mejor candidato. Pues aquí se trata de vedar al conocimiento público ciertos aspectos de la vida y la personalidad de cada cual. El problema aquí es el del alcance del derecho: ¿qué aspectos de la vida y de la personalidad de cada uno pueden sustraerse legítimamente en todo caso a las pesquisas de los demás? Es obvio que no puede tratarse de aquellos aspectos que cada uno decida: hay datos que hemos de proporcionar. Por ejemplo, nuestro nivel de estudios o nuestra profesión son datos que somos requeridos a manifestar con relativa frecuencia, así como -por seguir con los ejemplos- el nombre de nuestro cónyuge. Tenemos derecho a no proporcionar a nuestros conciudadanos información sobre nuestros ingresos, pero tenemos el deber de proporcionar esa información a las autoridades fiscales, etc., etc. ¿Qué ocurre con los datos relativos a nuestra salud? No estoy en condiciones de diseñar aquí ni siquiera un esbozo de una teoría acerca del alcance de la intimidad en el terreno de la salud, pero sí de decir algunas cosas. La primera es que la determinación del alcance de ese derecho depende también, como no puede ser de otro modo, de cuáles sean las razones que justifican el mismo. Y parece que esas razones tienen que ver con la dignidad y con la autonomía. Así, por ejemplo, el Tribunal Constitucional ha señalado que el derecho a la intimidad implica "la existencia de un ámbito propio y reservado frente a la acción y conocimiento de los demás, necesario -según las pautas de nuestra cultura- para mantener una calidad mínima de la vida humana" (STC 231/1988, de 2 de diciembre) y asimismo que "la intimidad personal y familiar es un bien [...] sin el cual no es realizable, ni concebible siquiera, la existencia en dignidad que a todos quiere asegurar la norma fundamental”. Y Carlos Nino ha indicado que el valor de la intimidad tiene que ver "con la necesidad de que los demás no adquieran un poder indebido sobre nuestra persona, de que nos sometan a situaciones de murmuración, burla y ridiculización, dada la intolerancia que a veces se tiene sobre otros hábitos de vida o rasgos de la personalidad, y el respeto a la libertad de cada uno de elegir 
su forma de vida"28. Del mismo modo que parece claro que estas razones exigen que se impida un acceso indiscriminado por parte de cualquiera a nuestro historial médico sin nuestro consentimiento, no veo para nada claro que exijan que, en situaciones de pandemia, no se nos pueda practicar una determinada analítica sin contar asimismo con nuestro previo consentimiento. Aguiló tendría que convencerme -esgrimiendo razones que en su texto ni siquiera esboza- de que la obligatoriedad de una prueba analítica es en todo caso lesiva de nuestra dignidad o proporciona a los demás un poder indebido sobre nuestra persona.

\subsection{Valores últimos y valores utilitarios, principios y directrices}

Quisiera ahora responder, para acabar, a los siguientes interrogantes de Aguiló relativos a las relaciones entre estos dos tipos de valores y estos dos tipos de normas:

“¿No os parece que establecer una conexión necesaria entre una forma de guiar la conducta o tipo de mandato (principio o directriz) con un tipo de valor (último o utilitario) resulta de una rigidez completamente injustificada? ¿No supone, además, olvidar que las formas de guiar la conducta son instrumentales en relación con los valores o bienes que se trata de proteger o de promocionar? [...] si resulta relativamente sencillo encontrar en nuestros ordenamientos ejemplos de normas (enunciados) que en su vertiente directiva se asemejan a directrices pero que protegen valores últimos y, a la inversa, normas que en el aspecto directivo se parecen a los principios en sentido estricto pero que están conectados con valores utilitarios ¿no os parece que la caracterización de la distinción que hacéis puede ser acusada de ideológica en el sentido de que presentáis como cualitativo lo que, en el mejor de los casos, no es más que cuantitativo? Y esta presentación ¿no tiene un sesgo injustificado que hace primar siempre los clásicos derechos de libertad frente a los de igualdad? ¿No pensáis que es más adecuado afirmar que en relación con cualquier valor (sea último o utilitario) pueden extraerse guías para la conducta tanto en el sentido de límite como en el de promoción dependiendo de los estados del mundo?”

Tengo la impresión de que, sin duda en parte por déficits en la presentación que Atienza y yo mismo hicimos del asunto, Aguiló ha entendido de forma algo inapropiada la distinción entre valores últimos (correspondientes a principios en sentido estricto) y valores utilitarios (correspondientes a directrices). Me parece que lo esencial de dicha distinción es lo siguiente: cuando atribuimos valor utilitario a una cierta propiedad (a un cierto bien, para expresarnos con más sencillez) lo que entra en línea de cuenta en nuestros juicios correspondientes es el monto global que de ese bien se haya

${ }^{28}$ C.S. Nino: Fundamentos de Derecho Constitucional, Astrea, Buenos Aires, 1992, p. 328. 
logrado producir, sin atender a los problemas de distribución. Operamos así, desde luego, cuando se trata de bienes públicos, que no son susceptibles de distribución, como un medio ambiente limpio o un patrimonio histórico o artístico adecuadamente conservado. Pero también operamos así en relación con bienes que sí resultan susceptibles de distribución como, por ejemplo, el empleo o el acceso a una vivienda digna y adecuada. Así, juzgaríamos como exitosa una política de empleo que en el lapso, digamos, de una legislatura, lograse reducir la cifra de desempleados del 15\%, digamos, al $5 \%$ de la población activa, por mucho que este éxito se distribuyera, desde luego, desigualitariamente, pues dicho 5\% no se beneficiara de él. E igualmente juzgaríamos como exitosa una política de vivienda que en el mismo lapso temporal lograse eliminar una parte sustancial de las infraviviendas existentes, realojando a sus ocupantes en viviendas dignas, por mucho que un número importante de personas continuase residiendo en infraviviendas. Y también, en algunas ocasiones, operamos así en relación con bienes que, como el respeto a la vida o a la integridad física, entendemos que deben ser adscritos a todos por igual. También en relación con este último tipo de bienes valoramos positivamente políticas que logren disminuir significativamente los casos en que tales bienes son lesionados. Por ejemplo, valoraríamos positivamente una política criminal que, en un cierto lapso, lograra disminuir a la mitad los casos de delitos contra la vida, aun cuando siguieran perdiéndose vidas humanas por delitos de este tipo.

En todos estos casos tratamos al bien de que se trate como portador de un valor utilitario. Obsérvese que puede tratarse (i) de bienes no susceptibles de ser distribuidos, ni igualitaria ni desigualitariamente, como es el caso del medio ambiente limpio; o bien (ii) de bienes susceptibles de ser distribuidos, pero en relación con los cuales el orden jurídico sólo prescribe la maximización y no un determinado modelo distributivo, como es el caso del empleo; o bien (iii) de bienes respecto de los que el orden jurídico prescribe la distribución igualitaria, como es el caso del respeto a la vida.

Cuando atribuimos valor último a un cierto bien, esta atribución implica -en sistemas jurídicos como el nuestro- que dicho bien debe adscribirse por igual a todos y cada uno. Esto es, atribuimos valor último a los bienes que, en la tripartición precedente, ocupan el casillero (iii). Y les atribuimos valor último porque entendemos que el respeto y la protección al disfrute igual de ese bien por todos y cada uno opera como límite a los cursos de acción admisibles para lograr la maximización de bienes de tipo (i), de tipo (ii) o del propio tipo (iii). Aguiló insinúa una orientación ideológica conservadora en nuestra construcción cuando pregunta si ella "no tiene un sesgo injustificado que hace primar siempre los clásicos derechos de libertad frente a los de igualdad”. Espero que lo expuesto hasta ahora haya hecho ver al lector 
lo infundado de esa atribución. Afirmar la primacía de los principios frente a las directrices lo que implica, bien al contrario, es que todos y cada uno de los seres humanos han de ser tratados como iguales en ciertos respectos importantes y que esta exigencia igualitaria prevalece, imponiendo límites, frente al diseño de políticas maximizadoras de cualquier tipo. Lo que sí implica, desde luego, la afirmación de esta primacía, y el conjunto de nuestra construcción, es la asunción de un cierto individualismo igualitario. Pero tal individualismo igualitario está, a mi juicio, más allá de los sesgos ideológicos “conservadores” o “progresistas” y se sitúa en el terreno común, en la base compartida a la que responden algunas de las líneas maestras de nuestros sistemas jurídicos. 
$\triangle \quad$ DOXA 28 (2005) 